\title{
ASSISTÊNCIA À SAÚDE DA MULHER NO CICLO GRAVÍDICO-PUERPERAL: AVALIAÇÃO DA ACESSIBILIDADE NA ATENÇÃO BÁSICA
}

\author{
Sheila Milena Pessoa dos Santos ${ }^{1}$, Jéssica Oliveira Rodrigues², Lais Vasconcelos Santos ${ }^{3}$, Lara Caline dos \\ Santos Lira ${ }^{2}$, Ueigla Batista da Silva ${ }^{2}$, Laianne Barbosa de Souza ${ }^{3}$
}

\begin{abstract}
RESUMO: Objetivou-se analisar a acessibilidade ao serviço de saúde da mulher no ciclo gravídico puerperal na percepção das usuárias. Para tanto, foi realizado um estudo exploratório, descritivo, de abordagem qualitativa, utilizando-se entrevista semiestruturada para coleta de dados. A composição da população foi de mulheres que estiveram ou estavam em período gravídico ou puerperal no período de janeiro de 2012 a abril de 2014. O critério de saturação foi adotado para definir a amostra, que alcançou 29 entrevistadas. Adotou-se para análise dos dados, a técnica categorial temática. Os resultados mostraram a existência de diversas barreiras geográficas, econômicas, socioculturais e organizacionais na assistência à mulher no ciclo gravídico e período pós-parto. Percebeu-se a necessidade de mudanças organizacionais de modo que reflita na melhoria da qualidade na assistência.
\end{abstract}

DESCRITORES: Acesso aos Serviços de Saúde; Gestantes; Período Pós-Parto.

\section{HEALTH CARE FOR WOMEN IN THE PREGNANCY-PUERPERIUM CYCLE: EVALUATION OF ACCESSIBILITY IN PRIMARY CARE}

ABSTRACT: This study aimed to analyze accessibility to the health service of women in the pregnancy-puerperium cycle, in the perception of the female service users. To this end, an exploratory, descriptive study was undertaken, with a qualitative approach, using a semistructured interview for data collection. The population was made up of women who had been, or were, in the pregnancypuerperium cyclein January 2012 - April 2014. The criteria of saturation was adopted for defining the sample, which reached the number of 29 interviewees. The thematic categorical technique was adopted for analysis of the data. The results showed the existence of various geographical, economic, sociocultural and organizational barriers in the assistance to women in the pregnancy cycleand in the postpartum period. It is possible to note the need for organizational changes which would be reflected in improvement in the quality of the care.

DESCRIPTORS: Accessibility of Health Services; Pregnant women; Postpartum Period.

\section{ASISTENCIA A LA SALUD DE LA MUJER EN EL CICLO GRAVÍDICO-PUERPERAL: EVALUACIÓN DE LA ACCESIBILIDAD EN LA ATENCIÓN BÁSICA}

RESUMEN: Estudio cuyo objetivo fue analizar la accesibilidad al servicio de salud de la mujer en el ciclo gravídico puerperal en la percepción de las usuarias. Para eso, se realizó un estudio exploratorio, descriptivo, de abordaje cualitativo, utilizándose entrevista semiestructurada en la obtención de datos. La composición de la población fue de mujeres que estuvieron o estaban en periodo gravídico o puerperal de enero de 2012 a abril de 2014. El criterio de saturación fue adoptado para definir la muestra, que tuvo 29 entrevistadas. Fue utilizada, para análisis de los datos, la técnica categorial temática. Los resultados mostraron la existencia de distintas barreras geográficas, económicas, socioculturales y organizacionales en la asistencia a la mujer en el ciclo gravídico y periodo posparto. Fue constatada la necesidad de cambios organizacionales que reflexionen en la mejoría de la cualidad en la asistencia.

DESCRIPTORES: Acceso a los Servicios de Salus; Gestantes; Periodo Posparto.

${ }^{1}$ Enfermeira. Doutoranda em Enfermagem. Docente do Curso de Enfermagem da Universidade Federal de Campina Grande. Campina Grande, PB, Brasil.

${ }^{2}$ Enfermeira. Universidade Federal de Campina Grande. Campina Grande, PB, Brasil.

${ }^{3}$ Discente de Enfermagem. Universidade Federal de Campina Grande. Campina Grande-PB, Brasil. 


\section{- INTRODUÇÃO}

As mulheres constituem mais da metade da população brasileira e são as principais usuárias do Sistema Único de Saúde (SUS) ${ }^{(1)}$. Compõem, portanto, um segmento social fundamental para as políticas de saúde, exigindo do SUS olhar ampliando para esta parcela da população, visto que diversos fatores sociais, econômicos e culturais, além de históricas desigualdades de poder entre mulheres e homens, implicam em forte impacto nas condições de saúde ${ }^{(2)}$.

Relacionado ao atendimento à gestante, salienta-se a importância da mulher, recém-nascido e família receberem atendimento adequado durante a gravidez, trabalho de parto, parto, período pós-parto e neonatal. A assistência deve ser pautada não só em procedimentos clínicos, mas em um conjunto de ações como promoção da saúde, acolhimento, estabelecimento de vínculo, entre outras tecnologias de forma a desenvolver a autonomia da mulher para o seu autocuidado ${ }^{(3)}$.

Para melhorar a assistência à gestante e recém-nascido, deve-se planejar ações considerando a identificação de fatores de risco relacionados com a mortalidade materna e neonatal, pois tal situação é um importante indicador que reflete as condições socioeconômicas, reprodutivas e, principalmente, as relacionadas à assistência pré-natal, ao parto e aos recém-nascidos ${ }^{(4)}$.

Nesta direção, em 2011 o Ministério da Saúde lançou como estratégia a Rede Cegonha, que objetiva: fomentar a implementação de um novo modelo de atenção à saúde da mulher e à saúde da criança com foco na atenção ao parto, ao nascimento, ao crescimento e ao desenvolvimento da criança de zero aos 24 meses $^{(5)}$.

Uma potente ferramenta de fortalecimento dos serviços para gestores, profissionais e usuários consiste na avaliação das ações em saúde. As avaliações da qualidade dos serviços prestados vêm se transformando numa ampla dimensão de estudos/pesquisas devido à necessidade de analisar os diversos contrastes encontrados nas instituições de saúde. Para tanto, existem alguns sistemas tanto nacionais quanto internacionais que se prestam a tarefa de avaliar e emitir pareceres objetivos sobre a qualidade dos serviços prestados ${ }^{(6)}$. Nessa perspectiva avaliativa, um eixo de análise pode partir da acessibilidade.

Compreende-se acessibilidade como o grau de ajuste entre as características dos recursos de saúde e as da população, no processo de busca da assistência à saúde. É resultante de uma combinação de fatores com distintas dimensões, que se classificam como de ordem geográfica, organizacional, sociocultural e econômica ${ }^{(7)}$.

Neste sentido, entende-se que a acessibilidade aos serviços de saúde deve contemplar tanto as características do serviço, no que diz respeito à oferta de atendimento em horários compatíveis, disponibilidade de profissionais preparados; acolhimento; condições do usuário em relação ao local que reside, sua disponibilidade de tempo, poder aquisitivo, hábitos e costumes e a relação entre eles(8). Além de acompanhamento eficaz do pré-natal, realização e recebimento em tempo hábil de exames laboratoriais e de imagens ${ }^{(7)}$. Todavia, percebe-se que estas ações não têm sido concretizadas na prática, tornando a qualidade do atendimento insatisfatória ${ }^{(8)}$.

No contexto atual, a problemática da acessibilidade insuficiente à assistência gestacional acarreta vulnerabilidade materno-infantil. Ao mesmo tempo, torna tanto o período gestacional quanto o puerperal desarticulados e fragmentados. Neste sentindo, surgiu o questionamento: Como ocorre a dimensão da acessibilidade de usuárias em período gravídico puerperal nos serviços de saúde na atenção básica?

Sendo assim, este estudo objetivou analisar a acessibilidade ao serviço de saúde da mulher no ciclo gravídico puerperal na percepção das usuárias. 


\section{METODOLOGIA}

Trabalho elaborado a partir do projeto de pesquisa "Acessibilidade ao serviço no ciclo gravídico puerperal: Uma avaliação da atenção à mulher na atenção básica", vinculado ao Programa de Reorientação da Formação Profissional em Saúde (PRÓ-Saúde) articulado ao Programa de Educação pelo Trabalho para a Saúde (PET-Saúde), da Universidade Federal de Campina Grande (UFCG) entre 2012 a 2014, conforme previsto no Edital nº 24 de 15 de dezembro de 2011 do Ministério da Saúde, por intermédio da Secretaria de Gestão do Trabalho e da Educação na Saúde (SGTES).

O estudo possui desenho exploratório e descritivo, com abordagem qualitativa. Foi realizado no município de Lagoa Seca, estado da Paraíba (PB) em duas unidades da Estratégia de Saúde da Família (ESF), contempladas com equipes do PRÓ/PET-Saúde.

A população foi composta por mulheres que estiveram ou estavam em período gravídico ou puerperal no período de janeiro de 2012 a abril de 2014, identificadas a partir de levantamento realizado nos livros de registros de cada Unidade de Saúde da Família (USF). Conseguinte ao levantamento empregou-se a estratégia de sorteio, realizado de forma aleatória dentre a população representativa para obter uma ordem das participantes.

Como critérios de inclusão foram aplicados: mulheres que realizaram pré-natal nas unidades participantes do estudo no período supracitado, não havendo limitação de idade, cor/raça ou deficiência física permanente ou transitória. O critério de exclusão adotado nesse estudo foi residência incompatível com a área de abrangência das USF selecionadas.

A coleta de dados foi caracterizada por entrevistas semiestruturadas. Adotou-se o critério de saturação para definir a quantidade expressiva para o estudo. O critério de saturação pode ser entendido pelo conhecimento do pesquisador do cenário do estudo, da lógica interna da coletividade e percebendo a intensidade das informações necessárias para seu trabalho ${ }^{(9)}$.

As entrevistas ocorreram no período de outubro a dezembro de 2014. Para realização das mesmas, as pesquisadoras se deslocaram até os domicílios das participantes. Empregou-se como guia um roteiro composto por questionamentos abertos, abordando as temáticas: Acessibilidade - Qualidade nos serviços de Saúde; Acessibilidade - Dimensões geográfica e organizacional; Acessibilidade Dimensões sociocultural e econômica.

Utilizou-se aparelho de MP3 para registrar as entrevistas. Considerando a avaliação de saturação, alcançou-se um total de 29 entrevistadas. O tempo de duração média foi de aproximadamente 10 minutos. Os diálogos foram transcritos e organizados. Os materiais advindos da coleta foram analisados conforme a análise de conteúdo do tipo categorial temática ${ }^{(10)}$.

A pesquisa foi aprovada em abril de 2014 pelo Comitê de Ética e Pesquisa do Hospital Universitário Alcides Carneiro, Parecer $n^{\circ}$ 869.561. A privacidade das participantes foi priorizada durante a coleta, tabulação dos dados e exposição das entrevistas, preservando anonimato e sigilo de dados; as entrevistadas foram representadas por meio do nome de pedras preciosas.

\section{RESUlTADOS}

A partir da análise dos dados, foi obtida uma categoria central "Os dizeres sobre qualidade e acessibilidade no SUS", que expressa as representações acerca do conhecimento sobre qualidade, acessibilidade e as dificuldades encontradas no serviço pelas mulheres. Dificuldades essas que conduziram à composição das demais categorias: $O$ caminho à unidade: tempo e distância como obstáculos; Gastos surgidos: dificuldades financeiras emergidas durante o pré-natal; Usuárias $\mathrm{x}$ Serviços: a dimensão sociocultural da acessibilidade e A (des)organização do serviço como fator prejudicial à assistência. 


\section{Os dizeres sobre qualidade e acessibilidade no SUS}

Sobre a qualidade atribuída aos serviços de saúde do SUS, a maioria das usuárias não conferiu qualidades positivas (9), enquanto outras consideraram regulares (7) e a minoria (6) atribuiu como boa a qualidade dos serviços pelo fato de conseguir ter acesso aos serviços.

Referente às atribuições negativas, nota-se pelas falas que a utilização do serviço acontecia de maneira ineficaz, faltando atendimento médico, medicação, exames.

A saúde do SUS não tem qualidade, tá péssima. É a pior saúde do mundo, a pessoa precisa das coisas e não consegue aí eles ficam de resolver as coisas e não resolvem nada. (Coral)

Os atendimentos do SUS eu acho que tem qualidade não, porque falta muita coisa, falta que a gente vai pro médico e não tem remédio, muitas vezes nem ficha pra anotar as consulta tem, eu acho que não é bom o atendimento. (Green Gold)

Ao avaliarem o serviço como regular, as usuárias associam boa qualidade à questão de ter atendimento sempre que precisam, no entanto para elas a qualidade não está boa por falta de insumos.

Nem em todos os serviços do SUS tem qualidade, falta muita coisa, falta os remédios, sobre exame que a pessoa pede e não passa. (Zircão)

O SUS só tem qualidade em algumas coisas, porque nem sempre consegue as coisas. (Topázio)

Para avaliação boa, os achados mostraram-se relacionados exclusivamente à oferta de atendimento médico, medicações, exames e acolhimento, ou seja, na percepção das mulheres qualidade do serviço de saúde é encontrar disponível o que procura.

[...] e assim que precisar ser atendido, ter exames, assim, tipo ultrassom, essas coisas seja mais fácil, né? [...]. (Ambar)

[...] pra ser bom tem que ter tudo; ter médico, médica, conversar [...]. (Esmeralda)

Bom atendimento é médico à disposição. (Amazonita)

Quando perguntadas sobre o que é acessibilidade, metade das mulheres afirmou que não sabiam, enquanto as que conheciam o termo restringiram as respostas ao fato de ter acesso aos serviços.

Sei não, sei como é isso não. (Coral)

Isso aí eu não entendo não. (Rodonita)

O deslocamento da casa da pessoa até o posto. (Seda)

Ter acesso, né? Ao que precisa. (Ambar)

Alusivo às dificuldades encontradas na procura aos serviços de saúde/unidades, depara-se com a identificação das dimensões de acessibilidade, evidenciando a geográfica, econômica, sociocultural e organizacional.

A lonjura de onde moro [...]. (Amazonita)

Ás vezes quando a pessoa precisa que custa demais, o tempo, a demora e eles não dão as coisas que a pessoa quer, às vezes pede uma coisa esse ano e só consegue para ano que vem. (Rubi)

A pessoa precisar das coisas e não conseguir, eles só fazem promessa, mas coisa boa pra saúde não fazem não. (Coral)

Muitos profissionais que trata a gente mal [...]. (Ágata)

Eles não querem atender a gente [...]. (Zircão)

Muitas vezes é a burocracia, ainda [...] a burocracia que impede que aconteça, né?. (Ambar) 
Os médicos que não tem, a demora pra marcar. (Topázio)

\section{O Caminho à unidade: tempo e distância como obstáculos}

Verificou-se que a maioria das mulheres reconheceu como barreira a distância entre a residência e o serviço de saúde:

É longe, mas eu venho a pé uma meia hora da minha casa até aqui. (Seda)

É distante, com certeza. Eu acho, vou de ônibus também tenho que ir de ônibus e muitas vezes a pé, né? (Green Gold)

Existe sim, porque é muito longe ir pro PSF, eu tenho que pegar 2 ônibus. (Coral)

Existe, à distância. Porque quando eu preciso ir, não dar pra ir a pé. (Rodonita)

Algumas mulheres afirmam que em decorrência da distância da USF, torna-se mais rápido procurar atendimento de urgência e emergência:

[...] E nem sempre a pessoa tem o dinheiro pra ir pra lá (ir para a USF), aí quando precisa mesmo é melhor e mais perto ir pro hospital. (Coral)

[...] É tanto que o povo vai pro hospital daqui é mais perto. (Cristal)

\section{Gastos surgidos: dificuldades financeiras emergidas durante o pré-natal}

Quando perguntadas sobre a situação financeira, as mulheres referiram maior dificuldade para realização de exames, conforme as seguintes falas:

Eu paguei todas os ultrassons, mulher, aí além de pagar isso eu pagava a passagem minha e da minha irmã pra gente ir pra Campina [cidade vizinha] bater, aí tu sabe, eu tomava emprestado. (Cristal)

Foi um pouco difícil porque a gente não tem renda fixa, a gente não tem estrutura familiar para tudo o que precisar ter a quantia ali. Pela prefeitura só consegui um ultrassom, as outras foram pagas [...]. (Amazonita)

Assim, aperto teve, mas deu para a gente contornar. Todas os ultrassons, foram muitas. Quando eu queria mais rápido assim, eu pagava. (Ambar)

Fiquei apertada porque sempre paguei [ultrassonografia e exames], eu não gosto de pedir nada pelo SUS não, acho que demora. (Fluorita)

Outras mulheres referiram como barreira econômica o deslocamento para o serviço de saúde:

[...] só pagar as passagem pra fazer o pré-natal [...]. (Cianita)

[...] aí ter que pagar o carro pra ir pra maternidade e depois voltar foi no sufoco [...]. (Coral)

\section{Usuárias x Serviços: a dimensão sociocultural da acessibilidade}

Nesta categoria, identificaram-se barreiras socioculturais no atendimento ao parto:

Têm muitos profissionais que trata a gente mal [...]. (Ágata)

[...] a médica me humilhou muito, ficava soltando piada pra mim porque eu tava gritando de dor e ela falando que esse povo tem três filhos e ainda fica com esses gritos. (Cristal)

Quem tem estudo fala umas coisas que a gente não entende. Tudo mentira pra enrolar a gente, aí a gente acredita na hora e volta pra casa acreditando que vai resolver. (Esmeralda) 
Eles deixam a pessoa sofrendo lá e nem ligam. (Turquesa)

\section{A (des)organização do serviço como fator prejudicial à assistência}

Algumas mulheres identificaram uma barreira organizacional no tempo de espera para as consultas: A gente espera muito, tá entendendo? Chega cedo e demora para ser atendida. (Ambar)

Assim, custa demais pra elas chegarem. Eles chegam de 08h30min-9h, aí a pessoa sai de casa logo cedo e elas demoram pra começar o atendimento. (Cristal)

O ruim é só o horário de lá, que pede pra chegar cedo e demora a atender. (Zircão)

O horário que é custoso porque a pessoa demora muito. (Turmalina)

Em relação ao atendimento no parto, a maioria falou que teve um bom atendimento e que conseguiu ter o bebê sem maiores problemas. Porém, determinados relatos das mulheres revelam a peregrinação em busca de uma maternidade, o que reflete uma barreira organizacional:

Eu fui direto pra maternidade aí não tinha vaga, né? Porque lá tava cheio, aí eles botaram eu pra [hospital], mas demorou um pouquinho lá, né? Se eu não tivesse corrido mais depressa, eu tinha ganhado no meio do caminho, só é ruim por isso, né?. (Dolomita)

Era pra eu ganhar no [hospital], mas não consegui ser atendida e fui pra UPA [Outro serviço]. (Ágata)

Outro problema organizacional identificado foi a não realização de visita puerperal pelos profissionais, a maioria das usuárias, não gestantes entrevistadas, disseram que não houve nenhuma visita domiciliar pelos profissionais que realizaram o pré-natal, grande parte das visitas foram realizadas por agentes comunitários de saúde.

\section{DISCUSSÃO}

Na visão das usuárias, a qualidade do atendimento está diretamente relacionada à garantia de acesso, portanto, quando se tem essa utilização negada, escassez de suprimentos e bloqueio de atendimentos, há uma má avaliação por parte daquelas que utilizam os serviços.

A maioria dos pacientes e familiares possui pouco conhecimento sobre o domínio técnico da qualidade, levando-os a terem suas opiniões refletidas por aspectos e representações culturais de que serviço bom é aquele que disponibiliza atendimentos com prescrições de medicamentos, exames e demais procedimentos ${ }^{(11)}$.

Há uma baixa satisfação dos usuários relacionada à não resolubilidade do sistema, como a falta de remédios, poucas vagas e demora em marcação de exames e consultas com especialistas ${ }^{(12)}$.

Visualiza-se na percepção do maior número de usuárias que qualidade ao serviço é atribuída ao simples fato de ter atendimento. Também se nota a valorização da figura do médico como o principal componente na USF.

Encontra-se uma visão reducionista da equipe de saúde da família por parte dos usuários, centrado no profissional médico, mostrando desconhecimento do papel dos outros integrantes da equipe e dando ênfase às ações diagnósticas e curativistas ${ }^{(13)}$.

Um fato que chama atenção no estudo é o número de mulheres que conheciam o significado de acessibilidade ser igual ao das mulheres que não souberam responder. Esse achado pode estar relacionado com o nível de escolaridade dessas usuárias, pois as que não sabiam responder tinham a escolaridade mais baixa.

A garantia do acesso universal no SUS decorre do reconhecimento de eventuais barreiras de acessibilidade vinculadas às necessidades e características da população ${ }^{(14)}$. Este reconhecimento é 
importante, pois pode impulsionar mudanças nas esferas governamentais, que eliminem ou atenuem essas barreiras, já que as dificuldades de acesso são as razões mais citadas para não realização do prénatal ${ }^{(15)}$.

O tempo de deslocamento determinado pela distância percorrida é uma das principais dificuldades ao acesso dos usuários para os serviços de saúde, pois constitui uma resistência imposta pelo espaço geográfico às trajetórias de deslocamento dos usuários em direção aos serviços ${ }^{(16)}$.

Percebe-se que a distância entre as residências e a USF configura-se como uma barreira de acesso, sobretudo para aquelas mulheres moradoras da zona rural. Um estudo realizado em um distrito sanitário do município de Salvador, estado da Bahia, no ano de 2009, mostrou que moradores de áreas mais distantes apresentam vulnerabilidade social aumentada e consequentemente situação de saúde pior, tendo fatores agravantes relacionados aos obstáculos geográficos para obtenção de acesso aos serviços $^{(17)}$.

Ademais, a busca por acesso leva usuários aos serviços de urgência e emergência. Notou-se que as usuárias deixam de utilizar a porta de entrada do SUS por problemas organizacionais e geográficos do município. Estudo apontou que a procura por unidades de pronto atendimento ocorre, pois há menor tempo de espera e facilidade no atendimento devido à organização de fluxo e o modelo de atendimento centrado no médico ${ }^{(18)}$.

Os obstáculos geográficos citados e o arranjo desordenado do serviço no município, com fragilidade no mapeamento das áreas de abrangência das USF estudadas, mostram a falta de transporte disponível para realização de visitas domiciliares e ausência de unidade âncora da unidade para assistir essas pessoas que moram mais distante e que não tem recursos para comparecer aos atendimentos.

Observou-se que a maioria das mulheres que relataram dificuldades financeiras no período gestacional foi para o custeio de Ultrassonografias (USG). No entanto, o Ministério da Saúde aborda que embora seja procedimento realizado rotineiramente, não existe, ainda, demonstração científica de que o mesmo tenha qualquer efetividade sobre a redução da morbimortalidade perinatal ou materna no pré-natal de baixo risco ${ }^{(19)}$.

O recurso financeiro necessário ao pagamento da tarifa do transporte representa uma barreira ao acesso dos usuários. Mesmo com o SUS sendo um sistema gratuito e universal, as famílias brasileiras mais abastardas financeiramente são as que mais gastam com a saúde, refletindo uma desigualdade nas despesas de saúde com prejuízo para os mais pobres ${ }^{(16)}$.

As dificuldades financeiras constituem obstáculo para os usuários do serviço, todavia, arcar com as despesas em situações de saúde é a maneira de buscar resolutividade para seus problemas. Tendo em vista que se depara com respostas demoradas dos mesmos, os usuários procuram por alternativas, tais como: ida a outros estabelecimentos do mesmo nível de atenção ou maior complexidade, automedicação e a atenção privada. Assim, percebe-se uma relação serviços de saúde-usuários que oferece materialmente o mínimo para sobrevivência, negam-lhes cidadania no cuidado à saúde, reafirmando um modelo de atenção excludente ${ }^{(20)}$.

Referente aos achados da dimensão sociocultural, nesta pesquisa notou-se que estes vão de encontro a uma pesquisa desenvolvida em maternidades São Paulo, no ano de 2008, que identificou nos relatos de maus tratos, forma grosseira de tratamento e que deixam 'sofrer' sem se importar ${ }^{(21)}$. Os serviços de saúde enfrentam diversas dificuldades econômicas e estruturais e encontram-se subjacentes aos maus-tratos vividos pelas usuárias, dessa forma, os aspectos socioculturais são refletidos na prática discriminatória(22).

Relacionada à acessibilidade organizacional, compreendida pelas facilidades oferecidas pelo serviço que favorecem o atendimento dos usuários ${ }^{(23)}$. Quando existem obstáculos, referem-se à demora em obter consulta, tipo de marcação de horário, tempo de espera por atendimento e /ou para fazer exames laboratoriais ${ }^{(7)}$.

Pesquisa mostrou que o tempo de espera para as consultas é característica marcante na assistência pré-natal, a longa espera causa cansaço, estresse e fome nas mulheres ${ }^{(24)}$. Isto indica que muitas vezes 
os serviços estão estruturados e organizados para atender suas próprias necessidades, estabelecendo horários de chegada que sejam mais adequados para o trabalho dos profissionais sem se preocuparem com a real necessidade dos usuários, além de desconsiderar seus compromissos na vida privada ${ }^{(22)}$.

Outra dificuldade encontrada neste estudo foi a peregrinação de mulheres em busca de maternidade para parir, relacionada à desvinculação entre os setores do pré-natal e parto. Tal fato também foi resultado de um estudo realizado em duas maternidades públicas na área urbana de São Luiz no estado do Maranhão em 2007, quando aproximadamente metade das participantes teve que ir a mais de uma maternidade para conseguir acesso, o que exemplifica a descontinuidade da assistência no ciclo gravídico-puerperal, bem como a falta de integração das unidades de saúde que prestam assistência durante o pré-natal e os estabelecimentos para o parto, gerando o não oferecimento de referência e segurança às pacientes ${ }^{(25)}$.

A visita puerperal é importante para orientar sobre amamentação, cuidados com o recém-nascido, avaliar interação da mãe com o recém-nascido, identificar situações de risco ou intercorrências e orientar sobre o planejamento familiar ${ }^{(19)}$. A ausência das visitas pode refletir na organização das equipes da USF, de modo que elas não encontram/priorizem tempo para sair das unidades de saúde e ir ao domicílio das usuárias.

\section{- CONCLUSÃO}

Como política inclusiva e integral, o SUS procura firmar a partir das ações estratégicas o engajamento do acesso universal aos serviços de saúde, possibilitando a efetivação e superação de carências históricas da oferta de atenção às diversas conjunturas que envolviam e ainda permeiam a saúde da mulher, especialmente de gestantes e puérperas, em todos os níveis de complexidade do sistema de saúde.

Os programas e estratégias com enfoque na saúde da mulher, a exemplo da Rede Cegonha, abarcam, ao menos no campo teórico, as principais necessidades ligadas direta ou indiretamente ao período gravídico-puerperal. A realidade, neste estudo, denota grandes vieses de cunho prático, o que inviabiliza a atenção à saúde integral das gestantes e puérperas e vai contra os preceitos teóricos como a efetivação da rede de atenção que garanta acesso, acolhimento e resolutividade.

As representações da acessibilidade ao serviço, que partiram da percepção das mulheres, demonstram que as barreiras no geral, se cruzam e convergem para a barreira organizacional, ao passo que cada dificuldade relatada na distância, no tempo de espera e por não conseguir realizar os exames refletem um despreparo organizacional do município.

Neste sentindo, é imprescindível compreender e considerar a participação e avaliação dos usuários como parte integrante do SUS, para buscar o rompimento das barreiras e qualidade nos serviços prestados, pois a opinião desses constitui-se em importante indicador de qualidade dos serviços de saúde. É destacada a importância de mudança diante das práticas gestoras e profissionais para que a inclusão da compreensão dos determinantes sociais reflita em uma práxis que reconheça as barreiras de acessibilidade existentes nas USF, e assim desenvolvam estratégias para minimizá-las ou até eliminálas do cenário analisado.

Este estudo abre subsídios para o desenvolvimento de outros, tendo como cenário os demais níveis de atenção; ampliação do foco representativo para o profissional de saúde e gestão, utilizando as prerrogativas das faces da organização, formação de parcerias e trabalho em rede que resultem na reflexão sobre a necessidade e estruturação para atendimentos de qualidade.

\section{- REFERÊNCIAS}

1. Ministério da Saúde (BR). Saúde da mulher: um diálogo aberto e participativo. Brasília: Conselho Nacional de Saúde; Ministério da Saúde; 2010. 
2. Presidência da República (BR). Secretaria de Políticas para as Mulheres. Plano Nacional de Políticas para as Mulheres. Brasília: Secretaria de Políticas para as Mulheres; 2013.

3. Duarte $\mathrm{SJH}, \mathrm{Mamede} \mathrm{MV}$. Ações do pré-natal realizadas pela equipe de enfermagem na atenção primária à saúde, Cuiabá. Cienc. enferm. [Internet] 2013; 19(1) [acesso em 25 fev 2015]. Disponível: http://dx.doi.org/10.4067/ S0717-95532013000100011

4. Kassara SB, Melo AMC, Coutinho SB, Lima MC, Lira PIC. Determinants of neonatal death with emphasis on health care during pregnancy, childbirth and reproductive history. J. Pediatr. [Internet] 2013; 89(3) [acesso em 22 fev 2015]. Disponível: http://dx.doi.org/10.1016/j.jped.2012.11.005

5. Ministério da saúde (BR). Portaria n. 1.459, de 24 de junho de 2011: Institui no âmbito do Sistema Único de Saúde - SUS - a Rede Cegonha. Diário Oficial da União, [Internet] 24 jun 2011 [acesso em 22 fev 2015]. Disponível: http://bvsms.saude.gov.br/bvs/saudele gis/gm/2011/prt1459_24_06_2011.html

6. Neves MAB. Avaliação da qualidade da prestação de serviços de saúde: um enfoque baseado no valor para o paciente. In: III Congresso Consad de Gestão Pública; 2010 mar. p. 1-17; Brasília, Brasil. Brasília: CONSAD; 2010.

7. da Silva LA, Alves VH, Rodrigues DP, Padoin SMM, Branco MBLR, de Souza RMP. A qualidade de uma rede integrada: acessibilidade e cobertura no pré-natal. J. res.: fundam. care. [Internet] 2015; 7(2) [acesso em 22 dez 2015]. Disponível: http://www.seer.unirio.br/index.php/cuidadofundamental/article/view/3744/pdf_1537

8. Alves MLP. Adequação da atenção à Saúde da Mulher e da Criança no município do Paudalho segundo olhar da Rede Cegonha. Plano de Intervenção de Especialização em Gestão de Sistemas e Serviços em Saúde. Centro de Pesquisas Aggeu Magalhães. 2011. [acesso em 25 fev 2015]. Disponível: http://www.cpqam.fiocruz.br/ bibpdf/2012alves-mlp.pdf

9. Minayo MCS. O desafio do conhecimento: pesquisa qualitativa em saúde. 14ª ed., São Paulo: Hucitec; 2014.

10. Bardin L. Análise de conteúdo. São Paulo: Edições 70; 2011.

11. Campos RTO, Ferrer AL, Gama CAP, Campos GWS, Trapé TL, Dantas DV. Avaliação da qualidade do acesso na atenção primária de uma grande cidade brasileira na perspectiva dos usuários. Saúde Debate. [Internet] 2014; 38(n. espec.) [acesso em 22 dez 2015]. Disponível: http://www.scielo.br/pdf/sdeb/v38nspe/0103-1104-sdeb-38spe-0252.pdf

12. Moimaz SAS, Marques JAM, Saliba O, Garbin CAS, Zima LG, Saliba NA. Satisfação e percepção do usuário do SUS sobre o serviço público de saúde. Physis. [Internet] 2010; 20(4) [acesso em 10 fev 2015]. Disponível: http:// dx.doi.org/10.1590/S0103-73312010000400019

13. Nery AA, Carvalho CGR, Santos FPA, Nascimento MSN, Rodrigues VP. Saúde da família: visão dos usuários. Rev. enferm. UERJ. [Internet] 2011; 19(3) [acesso em 19 fev 2015]. Disponível: http://www.facenf.uerj.br/v19n3/ v19n3a10.pdf

14. Trad LAB, Castellanos MEP, Guimarães MCS. Acessibilidade à atenção básica a famílias negras em bairro popular de Salvador, Brasil. Rev. Saúde Pública. [Internet] 2012; 46(6) [acesso em 17 fev 2015]. Disponível: http:// www.scielo.br/pdf/rsp/v46n6/10.pdf

15. Viellas EF, Domingues RMSM, Dias MAB, da Gama SGN, Theme Filha MM, Costa JV et al. Assistência prénatal no Brasil. Cad. Saúde Pública. [Internet] 2014; 30(Supl 1) [acesso em 02 fev 2015]. Disponível: http://dx.doi. org/10.1590/0102-311X00126013

16. de Almeida WS, Szwarcwald CL. Mortalidade infantil e acesso geográfico ao parto nos municípios brasileiros. Rev Saúde Pública [Internet] 2012; 46(1) [acesso em 22 fev 2015]. Disponível: http://dx.doi.org/10.1590/S003489102012005000003

17. Silva Júnior ES, Medina MG, Aquino R, Fonseca ACF, Vilasbôas ALQ. Acessibilidade geográfica à atenção primária à saúde em distrito sanitário do município de Salvador, Bahia. Rev. Bras. Saude Mater. Infant. [Internet] 2010; 10(Supl 1) [acesso em 22 fev 2015]. Disponível: http://dx.doi.org/10.1590/S1519-38292010000500005

18. Garcia VM, Reis RK. Adequação da demanda e perfil de morbidade atendida em uma unidade não hospitalar 
de urgência e emergência. Cienc Cuid Saude [Internet] 2014; 13(4) [acesso em 08 mar 2015]. Disponível: http:// eduem.uem.br/ojs/index.php/CiencCuidSaude/article/view/19127/pdf_245

19. Ministério da Saúde (BR). Cadernos de atenção básica. Atenção ao pré-natal de baixo risco. Brasília: Conselho Nacional de Saúde; Ministério da Saúde; 2012. 314-315 p.

20. Coelho EA, Silva CTO, Sena VC, Barros AR, Nascimento ER, Almeida MS. Demandas de mulheres por cuidado à saúde subsídios para construção da integralidade. Rev. Baiana de enferm. [Internet]. 2012; 26(6) [acesso em 08 fev 2015]. Disponível: http://www.portalseer.ufba.br/index.php/enfermagem/article/view/6850

21. de Aguiar JM, d'Oliveira AFPL. Violência institucional em maternidades públicas sob a ótica das usuárias. Interface (Botucatu) [Internet]. 2011; 15(36) [acesso em 24 fev 2015]. Disponível: http://dx.doi.org/10.1590/S141432832010005000035

22. Vasconcellos MPC, Chagas HMA. Quando a porta de entrada não resolve: análise das unidades de saúde da família no município de Rio Branco, Acre. Saúde Soc [Internet]. 2013; 22(2) [acesso em 13 mar 2015]. Disponível: http://www.revistas.usp.br/sausoc/article/download/76438/80151

23. Clementino FC, Miranda FAA. Acessibilidade: identificando barreiras na descentralização do controle da tuberculose nas unidades de saúde da família. Rev. enferm. UERJ [Internet]. 2010; 18(4) [acesso em 06 abr 2015]. Disponível: http://www.facenf.uerj.br/v18n4/v18n4a14.pdf

24. Líbera BD, Saunders C, Santos MMAS, Rimes FRSS, Baião MR. Avaliação da assistência pré-natal na perspectiva de puérperas e profissionais de saúde. Ciênc. saúde coletiva [Internet]. 2011; 16(12) [acesso em 08 abr 2015]. Disponível: http://dx.doi.org/10.1590/S1413-81232011001300034

25. Cunha SF, D’Eça Júnior A, Rios CTF, Pestana AL, Mochel EG, Paiva SS. Peregrinação no anteparto em São Luís Maranhão. Cogitare enferm. [Internet] 2010; 15(3) [acesso em 16 dez 2015]. Disponível: http://dx.doi.org/10.5380/ ce.v15i3.18885 